\title{
Brain Gain: Claims about its Size and Impact on Welfare and Growth Are Greatly Exaggerated*
}

\author{
Maurice Schiff \\ World Bank and IZA
}

\begin{abstract}
Based on static partial equilibrium analysis, the "new brain drain" literature argues that, by raising the return to education, a brain drain generates a brain gain that is, under certain conditions, larger than the brain drain itself, and that such a net brain gain results in an increase in welfare and growth due to education's positive externalities. This paper argues that these claims are exaggerated. In the static case, and based on both partial and general equilibrium considerations, the paper shows that $i)$ the size of the brain gain is smaller than suggested in that literature; ii) the impact on welfare and growth is smaller as well (for any brain gain size); iii) a positive brain gain is likely to result in a smaller, possibly negative, human capital gain; iv) an increase in the stock of human capital may have a negative impact on welfare and growth; and v) in a dynamic framework, the paper shows that the steady-state brain gain is equal to the brain drain so that a 'beneficial brain drain' cannot take place, and a net brain loss is likely during the transition.
\end{abstract}

Keywords: Brain Gain Size, Welfare, Growth, Exaggerated Claims

JEL Codes: D61, D62, F22, H20, H41, I12, J61

World Bank Policy Research Working Paper 3708, September 2005

The Policy Research Working Paper Series disseminates the findings of work in progress to encourage the exchange of ideas about development issues. An objective of the series is to get the findings out quickly, even if the presentations are less than fully polished. The papers carry the names of the authors and should be cited accordingly. The findings, interpretations, and conclusions expressed in this paper are entirely those of the authors. They do not necessarily represent the view of the World Bank, its Executive Directors, or the countries they represent. Policy Research Working Papers are available online at http://econ.worldbank.org.

*An early version of the paper was presented at the Royal Economic Society (RES) Meetings, March 21 23, 2005. A second version was prepared during my stay at ECLAC (CEPAL) as Visiting Scholar in April 2005, and I'd like to thank José Luis Machinea and Andrés Solimano for their kind invitation. Thanks are also due to| Mohammad Amin, Frédéric Docquier, Maurice Kugler, Caglar Ozden, Pierre Pestieau, Hillel Rapoport, Alan Winters and participants at the RES session on "The New Economics of the Brain Drain: View and Counterview" for useful comments, to Vlad Manole for research assistance and to Maria Kasilag for logistical support. 


\section{Table of Contents}

\section{Introduction}

1.1. Claims of the 'New Brain Drain' Literature

1.2. Main Findings

\section{Smaller Brain Gain: Partial Equilibrium}

2.1. Graphical Analysis

2.2. Heterogeneity

2.2.1. Individual Heterogeneity

2.2.2. Group Heterogeneity

2.3. Unskilled Migration

2.4. Brain Waste

2.5. Negative Brain Gain

2.6. Risk Aversion

\section{Smaller Brain Gain: General Equilibrium}

3.1. Public Expenditures and Tax Revenues

3.2. A Brain Gain that Results in a Smaller Human Capital Gain

\section{Smaller Impact on Welfare and Growth}

4.1. Brain Gain Size

4.2. General Equilibrium Effects

\section{Dynamic Implications of Endogenous Migration Probability and}

\section{Domestic Wages}

5.1. Partial Equilibrium and Exogenous Domestic Wage

5.1.1. Who Determines the Brain Drain?

5.1.2. Migration Probability and Evolution of the Brain Drain and Brain Gain

5.1.3. No Beneficial Brain Drain in the Steady State

5.2. Partial and General Equilibrium with Endogenous Skilled Wage Rate

\section{Empirical Evidence}

\section{Conclusion}




\section{Brain Gain: Claims about its Size and Impact on Welfare and Growth Are Greatly Exaggerated}

\section{Introduction}

The negative impact of the brain drain on the development of source countries has generally been accepted as received wisdom. However, a recent 'new brain drain' literature has challenged this view. The major claims of the new literature are described in Section 1.1, and Section 1.2 presents the paper's main findings.

\subsection{Claims of the 'New Brain Drain' Literature}

The traditional brain drain literature has viewed the exodus of human capital as something of a curse for developing countries, and has considered policies to counter it or reduce its negative impact on the emigration countries, including the taxation of migrants' income abroad (Bhagwati 1976, Bhagwati and Hamada 1976, Bhagwati and Wilson 1989). ${ }^{1}{ }^{2}$ That literature has recognized that the brain drain does confer certain benefits, including increased trade, remittances, knowledge, FDI (attributed in part to a "Diaspora" effect (Lucas 2005)), as well as the skills acquired by return migrants in the destination country. ${ }^{3}$

A benefit not considered in the traditional brain drain literature is the brain-draininduced 'brain gain,' a central feature of the 'new brain drain' literature. Since a brain drain implies that a share of skilled individuals will migrate and earn a higher wage abroad, the new brain drain literature posits that:

\footnotetext{
${ }^{1}$ This remains the view of the majority of analysts working on this issue (e.g., see Solimano 2001).

${ }^{2}$ On a nationalist view of the brain drain in this literature, see Patinkin (1968). On an internationalist view, see Johnson (1968) and Bhagwati and Wilson (1989).

${ }^{3}$ See also Ozden (Chapter 8 in this volume) and Javorcik, Ozden and Spatareanu (2004). They show that a larger stock of immigrants from a given source country to the US results in greater US outward FDI to that country, with the effect essentially due to skilled immigrants.
} 
i) the brain drain raises the expected return on education;

ii) this induces additional investment in education (a brain gain);

iii) this may result in a 'beneficial brain drain' or net brain gain, i.e., in a brain gain that is larger than the brain drain; and

iv) a net brain gain raises welfare and growth.

These results are said to hold independently of other potential effects of the brain drain on the level of education, whether through remittances or through the skills return migrants might have acquired in the destination countries.

Seminal papers in the new brain drain literature include Mountford (1997), Stark et al. (1997, 1998), Stark and Wang (2002), Stark (2004), Stark et al. (2004), Beine et al. (2001, 2003), Docquier and Rapoport (2004), and Vidal (1998). ${ }^{4}$ Their work has led to a reconsideration of the impact of the brain drain on the number of skilled individuals and on economic welfare and growth in the source country.

Most studies in that literature are theoretical, though empirical results are slowly emerging thanks to the work of Carrington and Detragiache (1998, 1999), Adams (2003) Docquier and Marfouk (Chapter 6 in this volume; 2004), and Dumont and Lemaitre (2005). ${ }^{5}$ These studies have estimated the stock of skilled migrants from developing countries who are living in OECD countries. ${ }^{6}$

\footnotetext{
${ }^{4}$ Commander, Kangasniemi and Winters (2004) provide a survey of the brain drain literature.

${ }^{5} \mathrm{An}$ analysis of regional differences in the brain drain is provided by Docquier et al. (2005).

${ }^{6}$ Carrington and Detragiache used the 1990 US census data to estimate the brain drain for a number of developing countries in 1990. Docquier and Marfouk (Chapter 6 in this volume) improved the measurement of the brain drain by expanding data sources to all OECD countries, estimating the brain drain for a larger number of developing countries, and doing so for the year 2000 as well as for 1990. They also provide estimates of the brain drain between developed countries.
} 
The number of skilled migrants--and their share in total migration--has risen dramatically in recent decades. Docquier and Hillel (2004) report that the number of migrants residing in OECD countries increased by 50\% between 1990 and 2000, with the increase in the number of skilled migrants equal to 2.5 times that of unskilled ones $(70 \%$ versus $28 \%$ ).

A case in point is the flight of human capital in the health sector, with the more extreme cases of emigration taking place in Sub-Saharan Africa and the Caribbean. For instance, Stalker (1994) reports that Jamaica has had to train five doctors in order to retain one, a brain drain of $80 \%$.

The necessity to assess the validity of the claims of the new brain drain literature has increased with the growing flight of skilled workers from developing countries and with the recent tilt towards skilled labor immigration policies by host countries. This paper provides such an assessment, based on a more detailed analysis of the relationship between the brain drain and brain gain.

The remainder of the paper is organized as follows. Based on partial equilibrium analysis, Section 2 shows why the brain gain is likely to be smaller than appears from the new brain drain literature. Section 3 does so from a general equilibrium perspective while Section 4 examines the impact of the brain gain on welfare and growth from a general equilibrium perspective. The latter has not been incorporated in the new brain drain literature, even though it is central to the analysis of the brain gain size and its impact on welfare and growth.

Section 5 provides a dynamic analysis of the new brain drain literature's claim regarding the net brain gain. Specifically, it examines whether a net brain gain-or 
beneficial brain drain--can possibly hold in the steady state and how it evolves in the transition period. Such analysis is crucial for understanding the impact of the brain drain on development and growth. The analysis in Section 5.1 is based on partial equilibrium and an exogenous domestic wage rate, while a partial and general equilibrium analysis with an endogenous wage rate is provided in Section 5.2. Section 6 describes the limited empirical evidence on this issue and Section 7 concludes.

\subsection{Main Findings}

This paper examines some of the assumptions underlying the findings of the new brain drain literature. It concludes that the impact of the brain drain on welfare and growth is likely to be significantly smaller, and the likelihood of a negative impact on welfare and growth significantly greater, than reported in that literature. This is based on the findings that i) the brain gain is smaller than has been obtained in the new brain drain literature, ii) the brain gain implies a smaller human capital gain, and iii) various negative effects of the brain gain on other sources of externalities human capital, welfare and growth have not been taken into account. These findings are derived from both partial and general equilibrium analysis.

Arguments for a smaller brain gain, resulting in a smaller net brain gain (brain gain minus brain drain) or net brain loss, and implying a smaller or negative impact on welfare and growth, include the fact that

i) abilities are heterogeneous and high-ability individuals-those who acquired skills when migration was not an option and the returns to 
education were lower--will emigrate, resulting in a lower average ability level for the educated people remaining in the source country;

ii) unskilled individuals migrate as well and benefit from it, implying that the brain drain has a smaller impact on the return to education;

iii) the education benefit is subject to a high degree of uncertainty (e.g., with respect to educational success, future employment abroad, host countries' future migration policies, and whether the individual will be among the few who migrate), and so is the cost of education (e.g., due to changes in the opportunity cost of time during the study period caused, say, by income or health problems in the student's family); and

iv) additional resources spent on education imply greater public and private expenditures and--since students do not work fulltime or at all--fewer taxes and less household income, resulting in a reduction in other public and private expenditures which also generate externalities, such as expenditures on health and public infrastructure, with a smaller and possibly negative impact on welfare and growth.

An analysis of the dynamics of the brain drain shows that the net brain gain is equal to zero in the steady state. In other words, a 'beneficial brain drain' cannot occur in the steady state. Moreover, a net brain loss is likely to hold during the transition.

Contributors to the early brain drain literature viewed the brain drain as entailing a loss for the developing source countries. An implication of the arguments presented in this paper is that their views were probably close to the mark. 


\section{Smaller Brain Gain: Partial Equilibrium}

Sections 2 and 3 argue that the brain gain is smaller than is claimed by the new brain drain literature. This section presents arguments based on partial equilibrium analysis. General equilibrium considerations are examined in Section 3.

\subsection{Graphical Analysis}

Before turning to these arguments, it seems useful to provide a simple graphical representation of the central issue examined in this paper. It reflects a static partial equilibrium view of the issue. Figure 1 shows, on the vertical axis, the brain drain $(B D)$, the brain gain $(B G)$ and the net brain gain $(N B G=B G-B D)$, as a proportion of the skilled labor force. These are shown as functions of the skilled-migration probability $p$ (i.e., the share of the brain drain in the skilled labor force).

The brain drain $B D$ is defined in the same way on both the horizontal and vertical axes, and it is therefore drawn as a 45-degree line rising from zero at $p=0$ to the entire skilled labor force at $p=1$. The brain gain $B G=0$ for $p=0$ (the no-migration situation) and $p=1$ (all newly educated individuals migrate), and positive for $0<p<1$.

Figure 1 presents two alternative brain gain curves, $B G=B G_{1}$ and $B G=B G_{2}$. In the case of $B G_{1--}$ the type of brain gain assumed in the new brain drain literature, the net brain gain $N B G_{1}$ is positive for $p<p_{1}$ and negative for $p>p_{1}$. Thus, a brain drain would result in a net increase in education for low migration probabilities (for a small brain drain relative to the skilled labor force).

This paper argues that the actual brain gain is closer to $B G_{2}$ than to $B G_{1}$ (or is actually equal to $\left.B G_{2}\right)$ with a negative net brain gain $\left(N B G_{2}<0\right)$ or a net brain loss for 
any $p>0$. Note also that $N B G$ is negative for large values of $p$, irrespective of whether $B G$ is equal to $B G_{1}$ or $B G_{2}$. This is one result on which the new brain drain literature and this paper agree.

\subsection{Heterogeneity}

\subsubsection{Individual Heterogeneity}

Assume, for simplicity, that ability — or talent--is distributed uniformly and that an individual's ability affects the benefit of education but not its cost which is a constant $C$. This is shown in Figure 2, which draws on Commander et al. (2004). Ability is measured on the horizontal axis and declines from right to left, with the highest ability equal to $A_{\text {MAX. }}$. The benefit and cost of education are measured on the vertical axis.

Figure 2 also shows three parallel lines declining from right to left, which depict the benefit of education under different circumstances. The lower line shows the benefit of education obtained in the absence of migration, i.e., the domestic wage. The top line shows the benefit of education obtained by migrants in the destination country, i.e., the foreign wage. The middle line shows the expected benefit of education, which is equal to a weighted average of the foreign and domestic wages. The weights are $p$ for the foreign wage) and $(1-p)$ for the domestic age, where $\mathrm{p}$ is the migration probability (share of migrants in the skilled population).

In the absence of migration, the equilibrium is at $A^{*}$. Under migration, equilibrium is at $A^{* *}$, with a brain gain equal to $\left(A^{* *}-A^{*}\right)$. However, one cannot simply compare $\left(A^{* *}-A^{*}\right)$ and $\left(A^{*}-A_{M A X}\right)$ because the two groups have different ability levels. Recalling that the distribution of abilities is uniform, individuals who acquired education 
in the absence of migration have an average ability level $A_{N M}=\left(A^{*}+A_{M A X}\right) / 2$, which is greater than the average ability level $A_{M}=\left(A^{* *}+A^{*}\right) / 2$ of those who acquired education once migration became possible. Since $A_{M}<A_{N M}$, it is not necessarily the case that a net brain gain takes place when the share of the brain gain (relative to the total number of educated individuals) $B G S=\left(A^{* *}-A^{*}\right) /\left(A^{* *}-A_{M A X}\right)$ is larger than the migration probability $p$.

In the absence of migration, the source country can draw on benefits from its most able individuals (with ability between $A_{M A X}$ and $A^{*}$ ). Recalling that the new brain drain literature assumes that skilled migrants are selected randomly among all skilled individuals with probability $p$, a share $p$ of migrants originates from both the more able group (between $A_{\text {MAX }}$ and $A^{*}$ ) and the less able group (between $A^{*}$ and $A^{* *}$ ).

Consequently, the skilled individuals remaining in the source country consists of a share $(1-p)$ of non-migrants from both the more able and the less able groups, with an average ability of $A_{M I G}=\left(A_{M A X}+A^{* *}\right) / 2$, compared to the higher average ability $A_{N M}=$ $\left(A^{*}+A_{M A X}\right) / 2$ of those who got educated in the absence of migration.

So, when $B G S=p$, i.e., when the number of skilled individuals in the source country is the same irrespective of whether migration takes place or not, migration results in a lower ability level in the source country by an amount equal to $A_{N M}-A_{M I G}=\left(A^{*}\right.$ $\left.A^{* *}\right) / 2$ and thus in a lower effective human capital stock.

Thus, a brain drain results in a negative net effective brain gain-i.e., a net effective brain loss--when the number of skilled individuals remains unchanged once migration takes place, i.e., when $B G S=p$, and results in a greater loss when $B G S<p$. A 
necessary but not sufficient condition for a net effective brain gain is $B G S>p$. In fact, a net effective brain loss may also occur in the case of $B G S>p .^{7}$

The arguments presented in the following sections strongly suggest that, even in the case of a homogeneous population with identical abilities, the net brain gain is likely to be negative. However, even if one assumes that the net brain gain is equal to zero, the reduction in the average ability level (a net effective brain loss) associated with migration under heterogeneity is likely to have negative implications for welfare and growth. ${ }^{8}$

\subsubsection{Group Heterogeneity}

Heterogeneity may occur across groups rather than across individuals. This situation is depicted in Figure 3 which shows three groups with different ability levels. In the absence of migration, two groups acquire education and the lowest-ability group does not. Once migration takes place, the expected return to education rises, though not sufficiently for the low-ability group which does do not acquire education in this case either. Thus, the brain drain does not result in a brain gain $\left(A^{* *}=A^{*}\right)$, and the source

\footnotetext{
${ }^{7}$ In an interesting paper, Fan and Stark (2005) present a model where decision-making takes place in three stages or less, and which generates equilibrium unemployment of skilled workers. The model assumes heterogeneity with respect to educational ability. However, given that ability in the job market tends to be positively related to educational ability, incorporating this feature would affect the results.

${ }^{8}$ In fact, the impact of migration on welfare and growth is likely to be significantly greater than might be inferred from the analysis above. Section 2.2.1 assumed, for simplicity, a uniform distribution of ability or talent. As Haque (2005) notes, there is evidence that the distribution of talent in developing countries is highly skewed (Power Law distribution), with a large number of individuals at most talent levels and a relatively small number of highly talented individuals. Thanks to recent advances in information and communication technology, there has been a dramatic acceleration in the globalization of knowledge. The highly talented individuals in developing countries tend to belong to the global knowledge community, cognizant of the latest advances in their field or contributing to them. Such individuals tend to generate very large positive externalities by imparting frontier knowledge to their colleagues, assistants and students, thereby also enabling those who benefit from that knowledge to further diffuse it. For instance, surgeons who are pioneers tend to form medical centers with teams of doctors working with them, and top scientists often generate top scientists. Haque (2005) provides an analysis that shows that, given that the cost of migration is lowest for highly talented individuals, they are the most likely to migrate, and their departure is likely to have an enormous impact on their country of origin that goes way beyond their tiny share in the skilled population.
} 
country loses some of its most able individuals. ${ }^{9}$ Alternatively, if the low-ability group acquires education, we obtain the same result as for individual heterogeneity (Section 2.2.1).

\subsection{Unskilled Migration}

Most analyses in the new brain drain literature examine the incentives to acquire education in the absence of migration and compare them to the incentives prevailing in the case of skilled worker migration. However, the reality is that out-migration of unskilled workers is substantial in most source countries, and their expected wage is higher under migration, just as is true for skilled workers. ${ }^{10}$

Denote the migration probability of skilled (unskilled) labor by $p(q)$, skilled (unskilled) variables by subscript $S(U)$, and destination country variables by *. In the absence of migration $(p=q=0)$, the education benefit or skill premium is

$$
B_{1}=W_{S}-W_{U}
$$

With a brain drain $(p>0, q=0)$, the expected benefit of education is

$$
B_{2}=\left(p W_{S}^{*}+(1-p) W_{S}\right)-W_{U}=\left(W_{S}-W_{U}\right)+p\left(W_{S}^{*}-W_{S}\right),
$$

\footnotetext{
${ }^{9}$ Stark (...) includes two groups in his model where, as assumed here, low-ability individuals do not acquire education when migration takes place, though high-ability individuals invest more in education when incentives improve. The model presented here assumes, as in most papers dealing with the brain gain, that individuals can only acquire a fixed amount of education.

${ }^{10}$ The new data set on migration by educational attainment put together by Docquier and Marfouk (Chapter 5 in this volume), and which covers 174 countries for 1990 and 195 countries for 2000, indicates that, for 1990, the average migration share-i.e., the migration probability--of the middle and high-education groups put together is about twice as large than in the low-education group. The recent immigration policy change favoring skilled migrants is reflected in the 2000 figures, with the share of the middle and higheducation groups about 2.5 times larger than in the low-education group. Though the share of the middle and high-education groups is larger than that of the low-education one, 2 to 2.5 times larger is less than infinitely larger, which is the assumption in the new brain drain literature where the share of migrants in the low-education group is set equal to zero.
} 
i.e., $B_{2}$ is equal to the domestic skill premium (as in equation (4)) plus the expected skilled labor migration premium.

With migration by both skilled and unskilled labor $(p, q>0)$, the expected benefit of education is

$$
B_{3}=\left(p W_{S}^{*}+(1-p) W_{S}\right)-\left(q W_{U}^{*}+(1-q) W_{U}\right)=\left(W_{S}-W_{U}\right)+p\left(W_{S}^{*}-W_{S}\right)-q\left(W_{U}^{*}-W_{U}\right) .
$$

Thus, $B_{3}$ is equal to the domestic skill premium plus the expected skilled labor migration premium minus the expected unskilled labor migration premium. Equations (4) and (5) show that a brain drain raises the expected return to education by the expected migration benefit:

$$
\Delta B_{S} \equiv B_{2}-B_{1}=p\left(W_{S}^{*}-W_{S}\right)>0 .
$$

This implies a brain gain, a basic finding of the new brain drain literature.

Equations (5) and (6) show that when both skilled and unskilled labor can migrate, the expected return to education falls compared to the case where only the skilled can migrate, with the change equal to

$$
\Delta B_{U} \equiv B_{3}-B_{2}=-q\left(W_{U}^{*}-W_{U}\right)<0,
$$

and the net benefit of education in this case is

$$
\Delta B_{E} \equiv \Delta B_{S}+\Delta B_{U}=p\left(W_{S}^{*}-W_{S}\right)-q\left(W_{U}^{*}-W_{U}\right)
$$

Thus, the impact of a brain drain on the return to education is smaller under the assumption that unskilled workers can migrate as well. This implies a smaller brain gain. $^{11}$

\footnotetext{
${ }^{11}$ How does the migration premium for skilled labor compare with that for unskilled labor? If the skills obtained in the source country differ substantially from the skills used in the destination country, the
} 


\subsection{Brain Waste}

Foreign workers are often hired to do jobs for which they are overqualified. Examples of Caribbean doctors or Eastern European scientists working as taxi drivers in some large US city are well known. Similarly, Moroccan doctors in France are typically working in less skilled positions (e.g., as interns) with significantly lower salaries.

Mattoo, Neagu and Ozden (2005) and Ozden (2005, Chapter 8)) refer to this phenomenon as a "brain waste" in their recent study of US immigration. They find that the extent of the brain waste-i.e., the difference in the skill content of a migrant's job versus that of a native of the destination country with similar education and experiencevaries according to origin country characteristics and US immigration policies.

Using the same notation as in Section 2.3 above, the expected benefit of education $B_{4}$ under skilled migration and brain waste $(B W)$ conditions is:

i) $B_{4}=W_{S}-W_{U}$ for $W_{B W}^{*}<W_{S}$ (no migration),

and

ii) $B_{4}=\left(p W_{B W}^{*}+(1-p) W_{S}\right)-W_{U}=\left(W_{S}-W_{U}\right)+p\left(W_{B W}^{*}-W_{S}\right)$ for $W_{B W}^{*}>W_{S}$.

In case (i), there is no brain drain or brain gain. In case (ii) where $W_{B W}^{*}>W_{S}$ and a brain drain takes place, the difference in benefits without brain waste $\left(B_{2}\right.$ in equation (5)) and with brain waste $\left(B_{4}\right.$ in equation $\left.(9 b)\right)$ is

migration premium for skilled labor is likely to be small. This might occur, for instance, in the case of lawyers if the legal systems differ between source and destination countries, or in the case of managers if source country firms are small, use outdated management methods and operate in a protected market, or simply because the skills are perceived to be inferior due to lack of information. Some of these issues are examined in the following section on the 'brain waste.' If the skills are similar and highly mobile, as in the case of scientists and engineers (especially if they studied in a destination country), one might expect the skill premium not to be very large either (unless a corner solution is reached where all the highly skilled leave). Thus, the migration premium for unskilled labor might be larger than that for skilled labor. 


$$
\Delta B_{B W} \equiv B_{4}-B_{2}=p\left(W_{B W}^{*}-W_{S}^{*}\right)<0, \partial W_{B W}^{*} / \partial B W<0 .
$$

The income loss reduces the impact of the brain drain on the benefit of education, implying a smaller brain gain. As can be seen from equation (10), the income loss depends on the wage gap between skilled and 'brain waste' jobs in the destination countries.

\subsection{Negative Brain Gain}

Assume that below a critical level of education $E_{0}$, some destination countries only hire unskilled workers, irrespective of their qualifications, but nevertheless attract both unskilled and skilled migrants because $W_{U}^{*}>W_{S}>W_{U}$. This should reduce the incentive to acquire education in source countries, and result in a negative brain gain. Note that this case constitutes an extreme version of the "brain waste" case examined above in Section 2.4.

The expected wage rate for unskilled labor is $E_{U}(W)=p W_{U}^{*}+(1-p) W_{U}$ and that for skilled labor is $E_{S}(W)=p W_{U}^{*}+(1-p) W_{S}$. The return to education in that case is $(1-p)\left(W_{S}-W_{U}\right)<\left(W_{S}-W_{U}\right)$, the return to education in the absence of migration. In other words, the migration option lowers the return to education, resulting in a negative net brain gain or net brain loss.

McKenzie (Chapter 5 in this volume) presents evidence of such an effect in the case of rural Mexico, with migration having a negative impact on education levels in general and more so for children with more educated parents. ${ }^{12} 13$.

\footnotetext{
${ }^{12}$ A more detailed analysis is provided in McKenzie and Rapoport (2005).
} 
This type of outcome might also prevail under less extreme forms of "brain waste." For instance, with the high demand for Filipino nurses, some medical doctors have gone back to school in order to become nurses, and some students have changed their study plans from medicine to nursing.

\subsection{Risk Aversion}

Risk aversion is likely to greatly reduce the brain-drain-induced brain gain. The new brain drain literature (e.g., Beine et al., 2001, 2003) claims that a net brain gain is more likely for low values of the migration probability $p$. As noted earlier, $E(W)=p W_{S}^{*}+(1-p) W_{S}$ and $\operatorname{Var}(W)=X *\left(W_{S}^{*}-W_{S}\right)^{2}$, where $X=(1-p)^{2}+p^{2}$ and $\partial X / \partial p=4 p-2$. Thus, $\partial X / \partial p>(<) 0$ for $p>(<)$.5. This implies that, for $p<.5, X$ increases as $p$ falls and so does $\operatorname{Var}(W)$. Hence, a low value for $\mathrm{p}$ is associated with a high value for $\operatorname{Var}(W)$, implying a smaller brain gain, with a smaller likelihood of a positive net brain gain. For high values of $p$, the new brain drain literature and this paper agree that the net brain drain is negative, even in the absence of risk-aversion.

There are of course many other sources of uncertainty associated with the fact that studies take time to complete and the future is unknown. Sources of uncertainty include success in school and the future level of host countries' skilled wages, the exchange rate, skilled wages at home, host countries' immigration policies, the probability of obtaining a job abroad, the allowed length of stay in the host country, and the value of the student's time for the family during the entire period of studies. That value rises when family

\footnotetext{
${ }^{13}$ Thus, migration not only lowers the level of education but also education inequality, with the latter due to a reduction in the rural educational level of those at the upper end of the distribution rather than an increase at the bottom of the distribution.
} 
income falls (due to crop failure, lower crop prices, illness, unemployment), which may force some students to abandon their studies and lose their investment.

In the analysis below, we only consider the uncertainty associated with the fact that individuals who consider whether to acquire additional education do not know whether they will be selected for migration when they complete their studies. Without loss of generality, assume that the cost of education $C=0$, and that risk aversion is represented by an expected utility function $E U$. Due to the concavity of the utility function, we have:

$$
U\left[p^{*} W_{s}^{*}+(1-p) * W_{s}\right]>E U=p U\left(W_{s}^{*}\right)+(1-p) U\left(W_{s}\right) .
$$

In other words, the expected utility of education's benefit is smaller than the utility of the expected benefit, implying a smaller brain gain. However, this is not the end of the story. The remaining question is whether the smaller brain drain is positive or zero.

Given that $p * W_{s}^{*}+(1-p) * W_{S}>W_{s}-C$, we have:

$$
U\left[p^{*} W_{s}^{*}+(1-p) * W_{s}\right]>U\left(W_{S}\right) .
$$

From equations (11) and (12), it follows that both $E U=p U\left(W_{s}^{*}\right)+(1-p) U\left(W_{s}\right)$ and $U\left(W_{s}\right)$ are both smaller than $U\left[p^{*} W_{s}^{*}+(1-p) * W_{s}\right]$. Thus, under risk aversion:

$$
E U=p U\left(W_{S}^{*}\right)+(1-p) U\left(W_{S}\right)>\text { or }<\text { than } U\left(W_{S}\right) .
$$

In other words, whether the expected utility from education with migration probability $p$ is larger or smaller than that from education in the absence of migration is ambiguous. If $E U=p U\left(W_{s}^{*}\right)+(1-p) U\left(W_{s}\right)>U\left(W_{s}\right)$, the brain gain is smaller than under risk neutrality, which reduces the likelihood of a net brain gain. If $E U=p U\left(W_{S}^{*}\right)+(1-p) U\left(W_{S}\right)<U\left(W_{S}\right)$, those individuals who did not find it in their 
interest to acquire education in the absence of migration (when the utility from education is $\left.U\left(W_{S}\right)\right)$ will certainly not acquire education under migration since their expected utility is even smaller in that case. In other words, there will be no brain gain, just a brain drain, implying a net brain loss.

Consequently, once skilled migration is allowed by the destination country, the brain drain under risk aversion results either in a smaller brain gain or in no brain gain, with the net brain gain smaller in the first case, and unambiguously negative in the second.

\section{Smaller Brain Gain: General Equilibrium Effects}

Spending additional resources on education means fewer resources available for other activities. Education is typically provided publicly and is heavily subsidized, though an important part of the costs are borne by the students or their families, the main one being the opportunity cost of the students' time.

In the case of tertiary education, a report by the World Bank (2000) states that "with developing country systems heavily dominated by public universities that tend to have low tuition fees, the costs fall predominantly on the state." The report estimates these costs relative to GNP for 1995, and finds that the worldwide average amounts to $77 \%$ of GNP per capita.

Lucas (2004) updated the figures for the year 2000 and, based on both sources, finds that 24 out of 90 countries had higher costs than the world average (Table 4.7). For Sub-Saharan countries, the cost relative to GNP was over $500 \%$ of the world average. Implications for the brain gain and human capital are examined below. 


\subsection{Public Expenditures and Tax Revenues}

Assuming that education is provided publicly, ${ }^{14}$ an increase in education will require additional funds. Moreover, time spent acquiring additional education means less work and lower tax revenues. Fiscally responsible authorities can respond to this situation by i) a tax increase, ii) a reduction in educational subsidies, or iii) a reduction in other public expenditures. ${ }^{15}$

A reduction in disposable income associated with the tax increase will reduce the demand for education and result in a smaller brain gain. ${ }^{16}$ Similarly, a reduction in educational subsidies will raise the cost of education and will also result in a smaller brain gain.

Implications for transition dynamics and for the steady state, these are the same as in Section 2.3 and 2.4.

The third option entails a reduction in non-educational public expenditures. To check the likelihood of substitution between the two categories of public expenditures, I estimated a relationship between public education expenditures $(\log E)$ and other capital expenditures $(\log K)$, both measured as a share of GDP, as well as a number of control variables. The sample covered over 70 developing countries, with an average of 7 observations per country and a total of over 600. A negative and significant relationship between $\log K$ and $\log E$ was obtained with a coefficient of -.47 , significant at the $1 \%$

\footnotetext{
${ }^{14}$ The results hold under privately provided education as well.

${ }^{15}$ Note that if fiscal considerations were unimportant because the impact on education is small, the weak education response to a brain drain would very likely imply a net brain loss. Thus, general equilibrium effects are especially important when the brain gain is large enough to matter.

${ }^{16}$ Of course, a smaller brain gain implies a smaller tax increase, which simply means that the equilibrium tax rate and brain gain must be solved simultaneously.
} 
level. This indicates that a one percent increase in the share of GDP devoted to education results in close to a half percent reduction in the share of other capital expenditures. ${ }^{17}$

This is unlikely to affect the extent of the brain gain, though it might affect welfare and growth (see Section 4.2) as well as the extent of the human capital gain. The latter is examined below.

\subsection{A Brain Gain that Results in a Smaller Human Capital Gain}

As shown in the previous section, an increase in public education expenditures is associated with a reduction in other public expenditures. Among those that might be curtailed are investments in the country healthcare infrastructure, maintenance, and the provision of healthcare services. This would have an adverse impact on the population's health status, and more so for poorer families that have little or no access to private healthcare.

Moreover, because individuals who are studying do not contribute to family income, expenditures will have to be reduced, especially in poorer families. If expenditures on healthcare are reduced, household health is likely to be adversely affected. And if food expenditures are reduced, the nutrition and health status of the family is likely to suffer as well.

In his AEA Presidential address entitled "Investment in Human Capital," Schultz (1961, p. 5) notes that, when adults have a meager diet and cannot work more than a few

\footnotetext{
${ }^{17}$ Interestingly, Beine et al. (2003)'s model includes a variable representing physical capital, R\&D expenditures and infrastructures in their growth regression, so that a reduction in that variable, associated with an increase in the investment in education, might impact welfare and growth.
} 
hours a day, food should be treated not just as consumption but as a productive input that raises the level of human capital. ${ }^{18}$

Furthermore, purchases of household appliances may have to be postponed, and may cause additional harmful effects. For instance, postponing the purchase of a refrigerator might not necessarily affect nutrient intake but it would most likely have adverse effects on nutritional status and health (Schiff and Valdés 1990a, 1990b). ${ }^{19}$

Since human capital depends on education as well as on health (Schultz, 1961, p.3), the impact of the brain drain on human capital is likely to be smaller than its impact on the brain gain. An educated workforce that is unable to work on a regular basis because of illness is unlikely to be very productive. In fact, reduced spending on health by individual families and the public sector might have devastating effects on the populations' health status and might lower the stock of human capital. ${ }^{20}$ Thus, a negative human capital gain might obtain. Whether the human capital gain is positive or negative, it is most likely to be smaller than the brain gain.

\footnotetext{
${ }^{18}$ Costa (2003) examines the long-run relationship between health and economic activity. Alderman et al. (2003), Martorell (1999) and Strauss and Thomas (1998) examine the link between nutrition and productivity.

${ }^{19}$ In the face of high food income elasticity estimates at low incomes and the implication that the poor suffered from malnutrition, the nutrition literature argued that what mattered is not food but nutrient intake and showed a low income elasticity for a variety of nutrients (calories, proteins, etc.) because, starting at low incomes, food expenditures shift from nutrient to non-nutrient attributes as income increases (due to greater demand for variety, ease of preparation and taste), with the implication that the poor do not suffer from malnutrition. Schiff and Valdés (1990a, 1990b) contributed to that literature by arguing that what matters is not nutrient intake but nutritional status, which depends on various household and community variables as well as on nutrients. Since investments in the former clearly depend on income (e.g., refrigerators and clean water), nutritional status is likely to be quite elastic with respect to income (and thus be worse for poor people), even if nutrient intake is not.

${ }^{20}$ This might occur because, even though a benign (and knowledgeable) government would be expected to take these negative externalities into account, individual households would not.
} 


\section{Smaller Impact on Welfare and Growth}

Based on the analysis in the previous sections, this section examines the impact of the brain gain on welfare and growth and compares it with claims made in the new brain drain literature.

\subsection{Brain Gain Size}

The previous section provided a number of arguments based on both partial and general equilibrium analytical frameworks and supporting the assertion of a significantly smaller brain gain and, by implication, a significantly smaller net brain gain than would appear from the literature. The obvious implication is that the impact on welfare and growth would also be significantly smaller.

\subsection{General Equilibrium Effects}

Romer's (1986) seminal paper on endogenous growth posited that, due to positive externalities, returns to physical capital were increasing, and that policies affecting the stock of physical capital could permanently change the economy's growth rate. Lucas (1988) also provided a model of endogenous growth but emphasized the role human capital. I assume in this section that both human and physical capital affect the economy's growth rate through contemporaneous externalities, intergenerational externalities (a la Beine et al., 2003), or both.

Section 3.1 listed three ways to deal with the higher public expenditures and lower tax revenues associated with a brain gain, namely higher taxes, lower education subsidies, or a reduction in other public expenditures. The first two lower the demand for 
education. The third one either lowers the level of human capital if, say, healthcare expenditures are reduced, or lowers other public expenditures that are likely to generate positive externalities.

The new brain drain literature assumes that education is the only sector that generates positive externalities. In fact, positive externalities are also generated by a number of other public (and private) sector activities as well. These activities include healthcare provision, investment in $\mathrm{R} \& \mathrm{D}$, and the provision of many other public goods where the presence of very large externalities and the temptation to free ride explains why these are provided publicly rather than privately.

In such a case, a government would maximize welfare through a tax and expenditure policy that results in the equalization of the per-currency-unit social marginal present value across all activities, whether private or public, consumption or investment, and pecuniary or not. Internalizing all the externalities associated with education, without taking into account the reduction in other expenditures and the consequent loss of other positive externalities, reduces the impact of the brain gain on welfare and growth and may result in a welfare loss and a lower growth rate.

The full effect of an increase in the brain drain would have to include the loss due to the brain drain itself. In other words, there are now two negative effects (the brain drain and the impact of the reduction in other expenditures) and a positive one (the brain gain). Thus, the likelihood of a beneficial brain drain seems much diminished. 


\section{Dynamic Implications of Endogenous Migration Probability and Domestic Wages}

Two assumptions prevalent in the new brain drain literature seem questionable. The first assumption is that the source country determines the migration probability (i.e., the share of migrants in the skilled population). The second one is that the migration probability is exogenous. Another assumption in the new brain drain literature is that the domestic (source country) skilled wage rate is exogenous. This need not be the case and the case of endogenous wages is considered as well. The analysis in Section 5.1 is based on partial equilibrium and an exogenous domestic wage rate, while a general equilibrium analysis with an endogenous wage rate is assumed in Section 5.2.

\subsection{Partial Equilibrium and Exogenous Domestic Wage Rate}

In this section, I argue that the migration probability is endogenous and examine the dynamics of the brain drain and the brain gain.

\subsubsection{Who Determines the Brain Drain?}

The first assumption described above relates to the source country's ability to determine the probability or rate of migration. This assumption is found in most studies in the new brain drain literature. For instance, Stark and Wang (2002) examine the role of a migration policy implemented by source country governments.

In fact, though trade and capital flows have been greatly liberalized, destination countries continue to impose strict barriers on immigration. Exceptions include a few repressive regimes - e.g., Cuba, Myanmar and North Korea--that deny their citizens the 
right to migrate. The number of such regimes has greatly diminished in recent years, mainly due to the collapse of the Soviet bloc.

Thus, except for a few countries, migration controls are firmly in the hands of destination countries' authorities. This is particularly true for the more skilled migrants who have less to gain by migrating illegally.

\subsubsection{Migration Probability and Evolution of the Brain Drain and Brain Gain}

The second assumption in the new brain drain literature is that the probability of migration is exogenously given and is unaffected by individuals' education decisions. However, I am not aware of any destination country immigration policy that stipulates that a specific percentage of a source country's skilled individuals is allowed entry. Rather, destination countries tend to use numerical quotas in order to restrict entry. In that case, the migration probability is endogenous, and its value depends on the size $S$ of the skilled population. These quotas are (almost) always filled. Denote the quota by $B D$ (the brain drain).

The models in the new brain drain literature typically start from a situation of zero migration and compare it with that of positive migration. The starting migration probability $p_{0}=B D / S_{0}$, where $B D$ is the brain drain which is determined by the destination country (i.e., the quota of skilled immigrants) and $S_{0}$ is the skilled population in period $t=0$ before migration takes place.

Models in the new brain drain literature assume that the migration probability $p$ is a constant that is determined exogenously. If so, those who are considering at $t=0$ whether to acquire additional education take the migration probability at $t=1$ (when they 
graduate) as being the one they observe at $t=0$ when they must make the education

decision. That probability is $p_{0}$. In other words, $p_{1}^{e}=p_{0}$, where $p_{1}^{e}$ is the probability expected to prevail at $t=1 .^{21}$ The fact that $p_{1}^{e}=p_{0}=B D / S_{0}$ is now positive raises the expected return on education and results in a brain gain $B G_{1}$. Thus, $B G_{1}$ is a function of $p_{1}^{e}=p_{0}$, i.e., $B G_{1}=B G\left(p_{0}\right)$. More generally:

$$
B G_{t}=B G\left(p_{t-1}\right), B G^{\prime}>0, B G^{\prime \prime}<0
$$

We start, at $\mathrm{t}=0$, from a steady-state situation where the number of individuals acquiring education before migration becomes an option is equal to the number of retirees (per period of time). With migration, the benefit of education increases, and new individuals decide to acquire education (the brain gain). Then, $S_{1}=S_{0}+\Delta S_{1}=S_{0}+\left(B G_{1}\right.$ $-B D)$. More generally:

$$
S_{t}=S_{t-1}+\Delta S_{t}=S_{t-1}+\left(B G_{t}-B D\right)=S_{0}+\sum_{i=1}^{t}\left(B G_{i}-B D\right) .
$$

Note that with the brain drain $B D$ determined by the host-country quota, the only variable is the brain gain $B G$.

\footnotetext{
${ }^{21}$ The model where such expectations are used is known as the cobweb model. The assumption of such expectations is certainly more plausible for the brain gain than in the case of crop prices, the case for which the cobweb model was originally developed. One reason is that the assessment about the probability of migration is made by different individuals every period, while the same farmers and traders operate over many periods and therefore have a better understanding of the markets in which they operate. A second reason is the availability of information. Information on (spot and futures) commodity prices is available in real time on a continuous basis through various electronic media outlets, which is certainly not the case for the future migration probability. Consequently, learning about the latter is much harder than for agricultural prices and is thus less likely, making the assumed expectations formation rule quite plausible in the migration case. Note that the same expectations rule obtains in the case of uncertainty (e.g., if there is a random disturbance term in equation (1)) in various rational expectations equilibrium models, resulting in a 'random walk' where $p_{t}=p_{t-1}+e_{t-1}$ and $e_{t-1}$ is a 'white noise' error term, so that $\mathrm{E}_{t-1}\left(p_{t}\right)=p_{t-1}$. Note that in this case, the expectations solution is the result of individuals exploiting all the available information rather than due to ignorance of how the market operates. Such a model may provide a good description of homogeneous commodities traded on a centralized commodities exchange but not for the case of migration.
} 


\subsubsection{No Beneficial Brain Drain in the Steady State}

The initial stock of educated people is $S_{0}$. The increase in the stock between periods 0 and 1 is $\Delta S_{1}=B G_{1}-B D$, which is either positive or negative. Assume that in the first transition path, $B G_{1}-B D>0$. In that case, the number of skilled people increases to $S_{1}>S_{0}$ and the migration probability decreases to $p_{1}=B D / S_{1}<p_{0}=B D / S_{0}$. From equation (14), $B G_{2}<B G_{1}$ and $\Delta S_{2}<\Delta S_{1}$. Over time, the stock $S_{t}$ increases at a decreasing rate until period $j$ where $\Delta S_{j}=0$, with a steady-state stock $S_{t}=S^{P}$ for all $t \geq j$.

In the second transition path, $\Delta S_{1}=B G_{1}-B D<0$. Then, $S_{1}<S_{0}, B G_{2}>B G_{1}$, $\left|\Delta S_{2}\right|<\left|\Delta S_{1}\right|$, and $\mathrm{S}_{t}$ falls at a decreasing rate. This process continues until period $k$ where $\Delta S_{k}=0$. The steady-state stock is $S_{t}=S^{N}$ for all $t \geq k$.

The first (second) transition path results in a steady-state stock $S^{P}\left(S^{N}\right)$ that is larger (smaller) than the initial one. Thus, $S^{P}>S_{0}>S^{N}$.

The previous sections presented a number of arguments in order to show that the brain gain is smaller than argued in the new brain drain literature and that the net brain gain is likely to be negative during the transition period). If so, migration leads to a decline in the stock of educated people or a smaller stock in steady state.

In the steady state, we have:

$$
\Delta S_{j}=\Delta S_{k}=B G-B D=0,
$$

where $B G$ is the value of $B G_{t}$ that solves equation (16).

Thus, the net brain gain $N B G \equiv B G-B D=0$ in the steady state, irrespective of the transition path. In other words, the brain gain is not large enough to result in a net brain gain--or beneficial brain drain--in the long run. This result is due to the assumption 
that the initial (pre-migration) situation is characterized by a steady state with a constant number of educated people.

Alternatively, assume that the initial, pre-migration, situation is characterized by a net increase in the number of educated people equal to $E$. Then, the steady-state solution under migration is: $E+B G-B D=0$, implying that $N B G \equiv B G-B D=-E<0$. In other words, the steady state is characterized by a net brain loss in that case.

These results hold under other expectation formation rules as well, including perfect foresight, rational expectations (see latter part of footnote 21) and adaptive expectations. ${ }^{22}$ The new brain drain literature claims that a brain drain results in a net brain gain under certain conditions. The analysis in this section shows that this result cannot hold in the long run.

Finally, a number of arguments have been presented in the paper to show that the brain gain is smaller than can be inferred from the new brain drain literature, and that the net brain gain is likely to be negative. That would imply a smaller stock of educated people in the steady state than in the pre-migration equilibrium.

\subsection{Partial and General Equilibrium with Endogenous Skilled Wage Rate}

Under partial equilibrium analysis, an endogenous domestic wage implies that the source country's skilled wage rate $W_{S}$ changes with the supply of educated people. In fact, $W_{S}$ falls (rises) for $N B G>(<) 0$ in period $\mathrm{t}=1$ (when migration starts). The positive (negative) $N B G$ falls (increases) faster because two forces are at play rather than one: the

\footnotetext{
${ }^{22}$ Convergence to the steady state is faster under perfect foresight and rational expectations, and is slower under adaptive expectations.
} 
reduction (increase) in the migration probability, as well as the fall (rise) in $W_{S}$. This results in a faster rate of convergence to the (unchanged) steady state.

Once might expect the same result to hold in general equilibrium, though this is not necessarily the case. For instance, assume a 2x2 Heckscher-Ohlin model with a Hicks-neutral technological advantage in the developed host countries (resulting in higher wages than in the developing source countries), and with skilled and unskilled labor inputs. ${ }^{23}$ In such a setting, a small economy's input and output prices are determined by world prices, domestic trade policy, and the technology gap. In that case, a positive (negative) net brain gain $N B G$ results in a reallocation of resources towards (away from) the skill-intensive activity and has no impact on input prices.

If the reallocation continues indefinitely, specialization will ensue, with all resources allocated to the skill-intensive sector for $N B G>0$ and to the unskilled-laborintensive sector for $N B G<0$. However, we have seen that the $N B G$ converges to zero as the economy approaches the steady state. If the steady-state is reached before specialization takes place, the analysis with an exogenous domestic wage carries through.

On the other hand, if specialization is reached before the steady state, the domestic wage rate $W_{S}$ falls (rises) as the number of skilled individuals increases (falls), and we are back to the partial equilibrium solution. The same outcome obtains for other partial and equilibrium models, such as imperfect competition models with product differentiation.

\footnotetext{
${ }^{23}$ The $2 \times 2$ model is assumed for simplicity. The same outcome obtains in an ' $\mathrm{m} \times \mathrm{m}$ ' model $(\mathrm{m}>2)$ with labor classified according to $\mathrm{m}$ skill categories.
} 


\section{Empirical Evidence}

This paper has argued that the net brain gain $N B G$ is closer to $N B G_{2}$ (see Figure 1) than to $N B G_{1}$. In fact, $N B G_{1}$ is quite similar to the function shown in Figure 6 in Docquier and Rapoport (2004), and reproduced here as Figure 4. The vertical axis measures the effect on the annual growth rate rather than the effect on NBG. Despite the fact that Figure 4 depicts an estimated relationship while Figure 3 does not, they tell a similar story, namely that a beneficial brain drain is more likely at low migration rates. As Beine et al. (2003, p.35) state: “ ... most countries combining low levels of human capital and low emigration rates of their highly-educated are positively affected by the brain drain."

On the other hand, and as shown in Figures 1 and 4, high migration rates (larger than $p_{1}$ ) inevitably result in a lower $N B G$ and rate of growth. Consequently, countries in Sub-Saharan Africa, the Caribbean as well as others that are suffering from massive outflows of medical personnel and other skilled workers cannot hope for much help from the brain gain effect, irrespective of whether $N B G=N B G_{1}$ or $N B G=N B G_{2}$.

Three studies have examined the impact of the brain drain on education levels or growth. As mentioned above, Beine et al. (2003) obtain a beneficial brain drain for countries with low levels of human capital and skilled migration rates. On the other hand, Faini (2005) finds little indication of a positive impact of the brain drain on growth in source countries, while Lucas (2005) - using two alternative definitions for the education variable - obtains a negative impact of the brain drain on education (see Table 1).

So far, empirical analysis consists of three studies generating three different sets of results with respect to the impact of the brain drain: a positive impact on the level of 
education (Beine et al.) for small brain drain rates, a negative impact on the level of education (Lucas) and no impact on growth (Faini). These results should be considered as preliminary, and additional conceptual and empirical work is needed before any conclusion can be reached.

\section{Concluding Comments}

Based on static analysis, this paper has shown that the size of the brain gain as well as its impact on welfare and growth are significantly smaller that found in the new brain drain literature and may even be negative. Arguments include the fact that

i) abilities are heterogeneous and high-ability individuals-those who acquired skills when migration was not an option and the returns to education were lower--will also emigrate, resulting in a lower average ability level for the educated people remaining in the source country;

ii) unskilled individuals migrate as well and benefit from it, implying that the brain drain has a smaller impact on the return to education;

iii) the education benefit is subject to a high degree of uncertainty (e.g., with respect to educational success, future employment abroad, host countries' future migration policies, and whether the individual will be among the few who migrate), and so is the cost of education (e.g., due to changes in the opportunity cost of time during the study period caused, say, by income or health problems in the student's family);

iv) brain waste, which in extreme form results in a negative brain gain; and 
v) additional resources spent on education imply greater public and private expenditures and--since students do not work fulltime or at all--fewer taxes and less household income, resulting in a reduction in other externality-generating public and private expenditures, such as expenditures on health and public infrastructure, resulting in a smaller and possibly negative impact on welfare and growth.

An analysis of the dynamics of the brain drain shows that the net brain gain is equal to zero in the steady state. In other words, a 'beneficial brain drain' cannot occur in the steady state. Moreover, a net brain loss is likely to hold during the transition.

Dynamic aspects of the brain-drain-induced brain gain are also examined in this paper. It is shown that the brain drain is equal to the brain gain in steady state, so that a beneficial brain drain cannot take place in the long run. Moreover, the net brain gain is likely to be negative during the transition period, so that the new steady-state is characterized by a lower level of the education stock.

Contributors to the early brain drain literature viewed the brain drain as entailing a loss for the developing source countries. An implication of the arguments presented in this paper is that these contributors were close to the mark.

The new brain drain literature and this paper are in agreement on one point, namely that the net brain gain is negative for larger migration probabilities and certainly in the most severe brain drain cases. In other words, the new brain drain literature offers no solution to the most severe brain drain problems. This includes the exodus of 
healthcare providers from Sub-Sahara Africa--the world's poorest region--and the Caribbean

Consequently, policies to slow down or stop the exodus of skilled labor are urgently needed. This issue is beyond the scope of this paper, though it might be worth examining the possibility of i) host countries supporting - both financially and with expertise--education in source countries in the areas where they expect to need skilled labor in the future, together with ii) instituting programs of temporary migration (possibly with migrant circulation). This should enable both source and host countries to benefit.

\section{References}

Adams, R. 2003. "International Migration, Remittances and the Brain Drain: A Study of 24 Labor-Exporting Countries.” Policy Research Working Paper No. 2972. World Bank.

Alderman, H., J. Hoddinet and B. Kinsey. 2003. "Long Term Consequences of Early Childhood Malnutrition." Mimeo. Deptartment of Economics. Dalhousie University. Halifax.

Beine, M., F. Docquier and H. Rapoport. 2001. "Brain Drain and Economic Growth: Theory and Evidence.” Journal of Development Economics 64 (1): 275-89.

Losers." IZA Discussion Paper No. 819 (July).

Bhagwati, J. 1976. "The international brain drain and taxation. A survey of the issues." In J. Bhagwati (ed.). The brain drain and taxation. Theory and empirical analysis. North Holland: Amsterdam. Cambridge, Mass.

and J.D. Wilson. 1989. Income Taxation and International Mobility. MIT Press:

Carrington, W.J. and E. Detragiache. 1998. "How Big is the Brain Drain?" IMF Working Paper No. 98. Washington, D.C.

(June): $\overline{46-49 .}$

and _. 1999. "How extensive is the brain drain?" Finance \& Development

Commander, S., M. Kangasniemi and L. A. Winters. 2004. "The Brain Drain: Curse or Boon? A Survey of the Literature." In R.E. Baldwin and L. A. Winters (eds.) Challenges to Globalization. Analyzing the Economics. University of Chicago Press: Chicago and London. 
Costa, D. L. 2003 (editor). Health and Labor Force Participation Over the Life Cycle: Evidence from the Past. Chicago and London: University of Chicago Press.

Docquier, F. and A. Marfouk. 2005. "International Migration by Educational Attainment (1990-2000)." Chapter 5 in this volume.

- Early version published as Policy Research Working Paper 3381. World Bank.

, O. Lohest and A. Marfouk. 2005. "Brain drain in developing regions (19902000)." Mimeo. CADRE. University of Lille, and Research Program on International Migration and Development. International Trade Unit. DEC Research Group. World Bank.

Docquier, F. and H. Rapoport. 2004. "Skilled Migration: The Perspective of Developing Countries.” Policy Research Working Paper No. 3382. World Bank (August).

Countries - A Survey.” Mimeo. Bar-Ilan University (December, draft).

. 2004. "Skilled Migration and Human Capital Formation in Developing

Dumont, J.-C. and G. Lemaitre. 2005. "Counting immigrants and expatriates in OECD countries: a new perspective. Directorate for Employment, Labour and Social Affairs. Paris: OECD.

Faini, R. 2005. "Does the brain drain boost growth?" Mimeo. University of Rome, and Research Program on International Migration and Development. International Trade Unit. DEC Research Group. World Bank.

Fan, C. S.. and O. Stark. 2005. "Addition through Depletion: The Brain Drain as Catalyst of Human Capital Formation and Economic Betterment.” Mimeo. University of Klagenfurt.

Haque, N. Ul. 2005. “'Winner-Take-All' Distribution of Talent: A New Approach to the Brain Drain." Research Program on International Migration and Development. International Trade Unit. DEC Research Group. World Bank.

Jasso G. and Rosenzweig M.R. 1995. "Do immigrants screened for skills do better than family reunification immigrants?” International Migration Review 29 (1): 85-111.

Javorcik, B. S., C. Ozden and M. Spatareanu. 2004 (Dec.) "Does South-North Brain Drain Contribute to North-South FDI?" Mimeo. Research Program on International Migration and Development. International Trade Unit. DEC Research Group. World Bank.

Kugler, M. and H. Rapoport. 2005. "Skilled Emigration, Business Networks and FDI Inflows." Paper presented at the Royal Economic Society (March). Nottingham.

Lopez, R. and M. Schiff. 1998. "Migration and the Skill Composition of the Labor: The Impact of Trade Liberalization in LDCs." Canadian Journal of Economics 31 (2): 318-36.

Lucas, R. E., Jr. 1988. "On the Mechanics of Economic Development." Journal of Monetary Economics.

Lucas, R. E. B. 2004. International Migration Regimes and Economic Development. Report prepared for the Swedish Ministry of Foreign Affairs (EGDI). 
Lucas, R. E. B. 2005. “International Migration: Lessons from Recent Data.” Presentation in the Migration Seminar Series. World Bank. Washington, D.C. (March 8).

Martorell, R. 1999. "The Nature of Child Malnutrition and its Long-Term Implications." Food and Nutrition Bulletin 20: 288-92.

Mattoo, A., I. C. Neagu and C. Ozden. 2005. "Brain Waste? Educated Immigrants in the US Labor Market." Mimeo. Research Program on International Migration and Development. International Trade Unit. DEC Research Group. World Bank. (March).

McKenzie, D. and H. Rapoport. 2005. "Migration Incentives, Migration Networks and the Dynamics of Education Inequality in Rural Mexico." Paper presented at the IADB "Economic Integration, Remittances, and Development" Conference.

McKenzie, D. 2005. "Beyond Remittances: The Effects of Migration on Mexican Households." Chapter 5 in this volume.

Mountford, A. 1997. "Can a brain drain be good for growth in the source economy?" Journal of Development Economics 53 (2): 287-303. this volume.

Ozden, C. 2005. "Skilled Migrants in the US: Brain Drain or Brain Waste?" Chapter 8 in

Patinkin, D. 1968. “A 'Nationalist' Model.” In Adams, W. (ed.) The Brain Drain. New York: Macmillan.

Romer, P. 1986. "Increasing Returns and Long Run Growth." Journal of Political Economy 94: 1002-37 (October).

SOPEMI. 2003. Trends in International Migration. OECD. Paris.

Schiff, M. and A. Valdés. 1990. "Nutrition: Alternative Definitions and Policy Implications." Economic Development and Cultural Change (January).

and _ . 1990. "Poverty, Food Intake and Malnutrition: Implications for Food Security in Developing Countries." American Journal of Agricultural Economics (December).

Schultz, T. W. 1961. "Investment in Human Capital." AEA Presidential Address. American Economic Review 51 (1): 1-17.

Solimano, A. 2001. "International Migration and the Global Economic Order: An Overview." Mimeo. World Bank. Washington, DC.

Stalker, P. 1994. The work of strangers. A survey of international labour migration. International Labour Office: Geneva.

Stark, O. "Rethinking the Brain Drain.” 2004. World Development 32 (1): 15-22.

, A. Casarico, C. Devillanova and S. Uebelmesser. 2004. "The New Economics of the Brain Gain: Mapping the Gains." Paper presented at the 'Conference on Advanced Perspectives on Migration and Mobility.' University of Bonn (Sept. 30-Oct.1). 
, C. Helmenstein and A. Prskawetz. 1997. "A brain drain with a brain gain." Economics Letters 55: 227-34.

, C. Helmenstein and A. Prskawetz. 1998. "Human capital depletion, human capital formation, and migration: a blessing or a "curse"?" Economics Letters 60: 363-67.

, and Y. Wang. 2002. "Inducing Human Capital formation: Migration as a Substitute for Subsidies." Journal of Public Economics 86 (1): 29-46.

Strauss, J. and D. Thomas. 1998. "Health, Nutrition and Economic Development." Journal of Economic Literature 36 (2): 766-817.

Vidal, J.-P. 1998. "The effect of emigration on human capital formation." Journal of Population Economics 11 (4): 589-600.

Warner, A. 2002. "International Wage Determination and Globalization” (March).

Winters, L. A. 2005. "Skilled Labor Mobility in Europe 1945-2000. Mimeo. Development Economics Research Group. World Bank.

World Bank. 2000. 


\section{Table 1: Impact of the Brain Drain on Education}

\begin{tabular}{|l|c|c|c|}
\hline \multirow{2}{*}{} & \multicolumn{2}{|c|}{$\begin{array}{c}\text { log increment of tertiary } \\
\text { education at home 95-2000 } \\
\text { (Change in Stocks) }\end{array}$} & \multirow{2}{*}{$\begin{array}{c}\text { log tertiary } \\
\text { enrollment }\end{array}$} \\
\cline { 2 - 3 } & ALL & Low Income & \\
\hline Ln & -0.366 & -0.331 & -0.256 \\
brain drain & $(3.53)$ & $(2.21)$ & $(2.32)$ \\
\hline Ln & 0.567 & 1.400 & 0.691 \\
income & $(9.11)$ & $(9.48)$ & $(9.31)$ \\
\hline Ln & 0.887 & 0.797 & -0.112 \\
population & $(14.95)$ & $(8.74)$ & $(2.18)$ \\
\hline No. of obs. & 91 & 39 & 55 \\
R-square & .90 & .91 & .69 \\
\hline
\end{tabular}

Table reproduced from Lucas (2005).

OLS; SE Robust; t-stats in parentheses; intercepts included, not shown. Brain Drain: OECD (2000)

Tertiarv Enrollment: UNESCO (several vears) 
Figure 1: Brain Grain (BG), Brain Drain (BD) and Net Brain Gain (NBG = BG-BD)

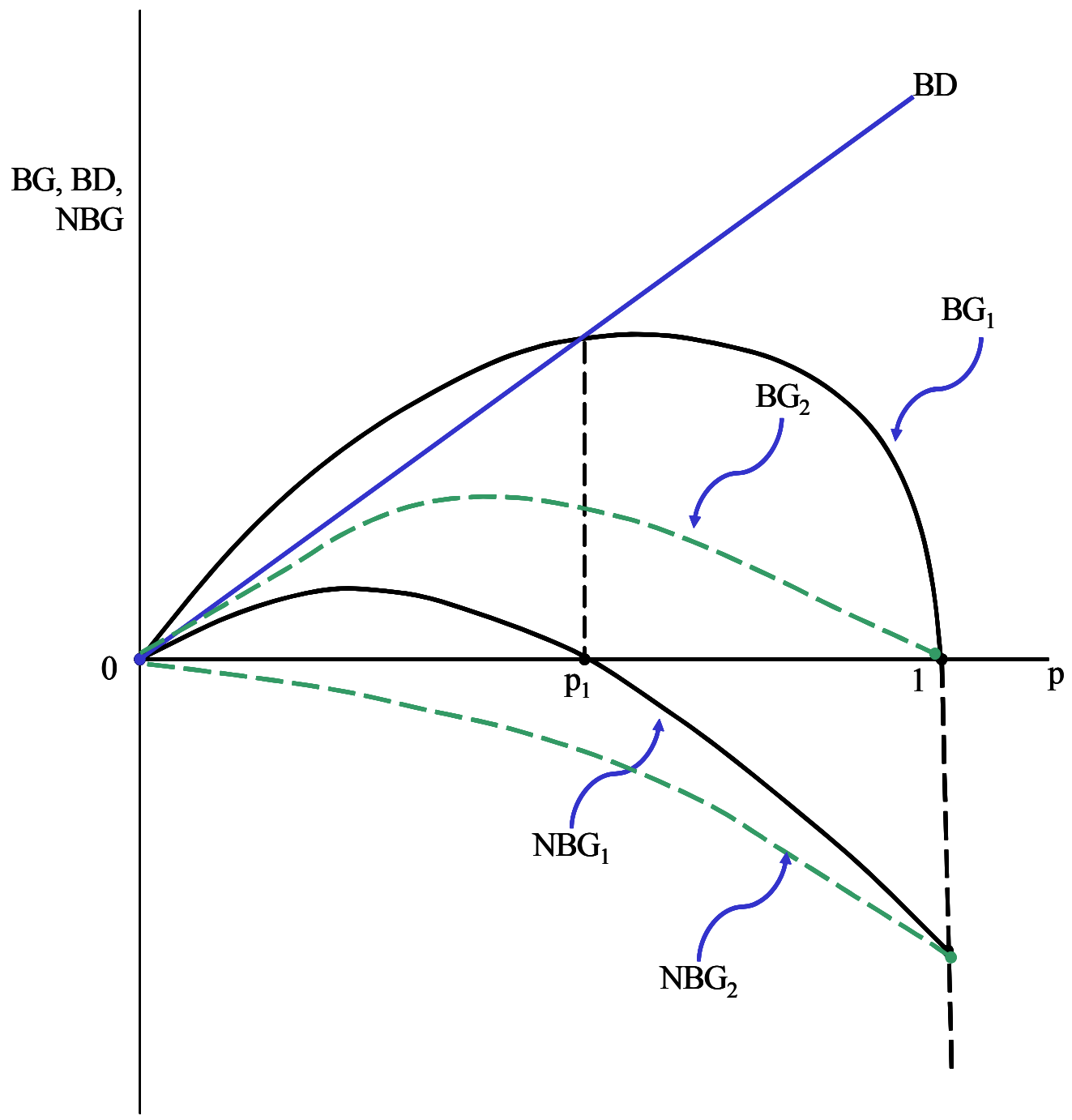

Horizontal axis: $\mathrm{p}=$ migration probability;

Vertical axis: share of migrants in skilled population. 


\section{Figure 2: Endogenous Migration Probability}

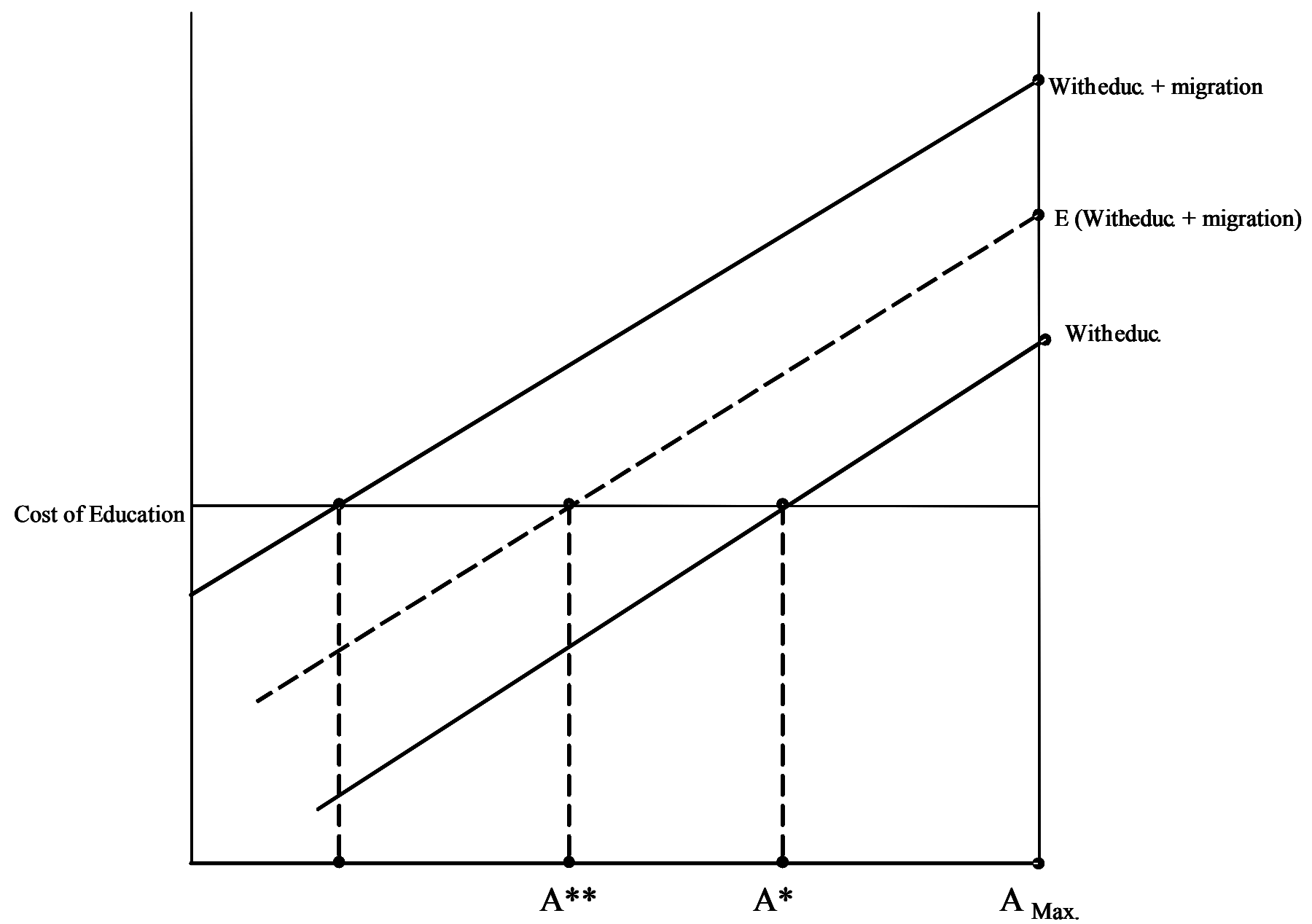

Horizontal axis: ability, increasing from left to right.

Vertical axis: benefit from education as a function of ability.

The lower line is the skilled domestic wage (the return to education in the no-migration case);

The top line is the skilled foreign wage (the return to education under migration);

The middle line is the expected wage (weighted average of foreign wage (with weight $p$ ) and domestic wage (with weight $1-p$ ). 


\section{Figure 3: Group Heterogeneity}

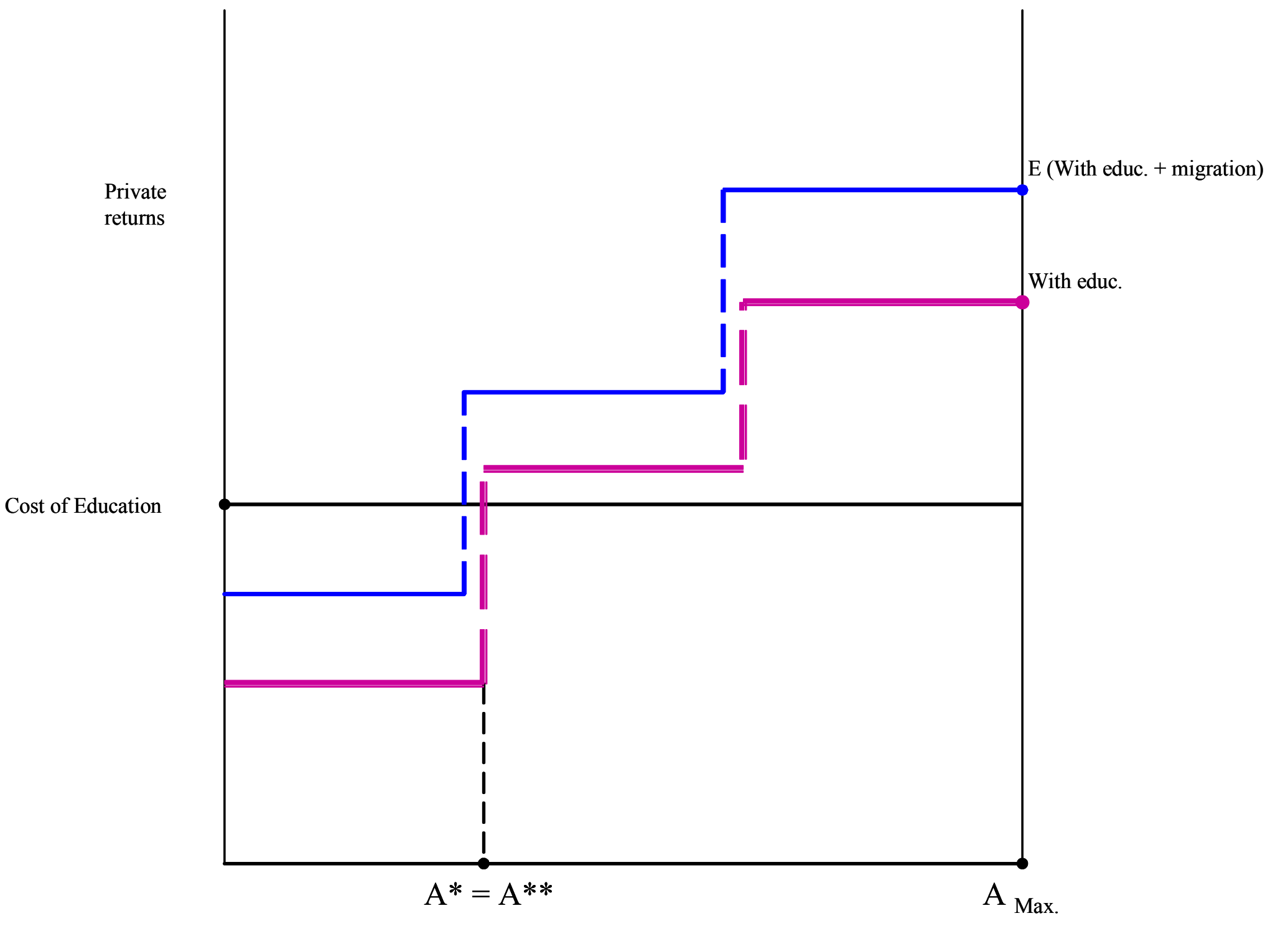


Figure 4. Brain drain and LDC's growth

(with $2^{\text {nd }}$ order polynominal trend)

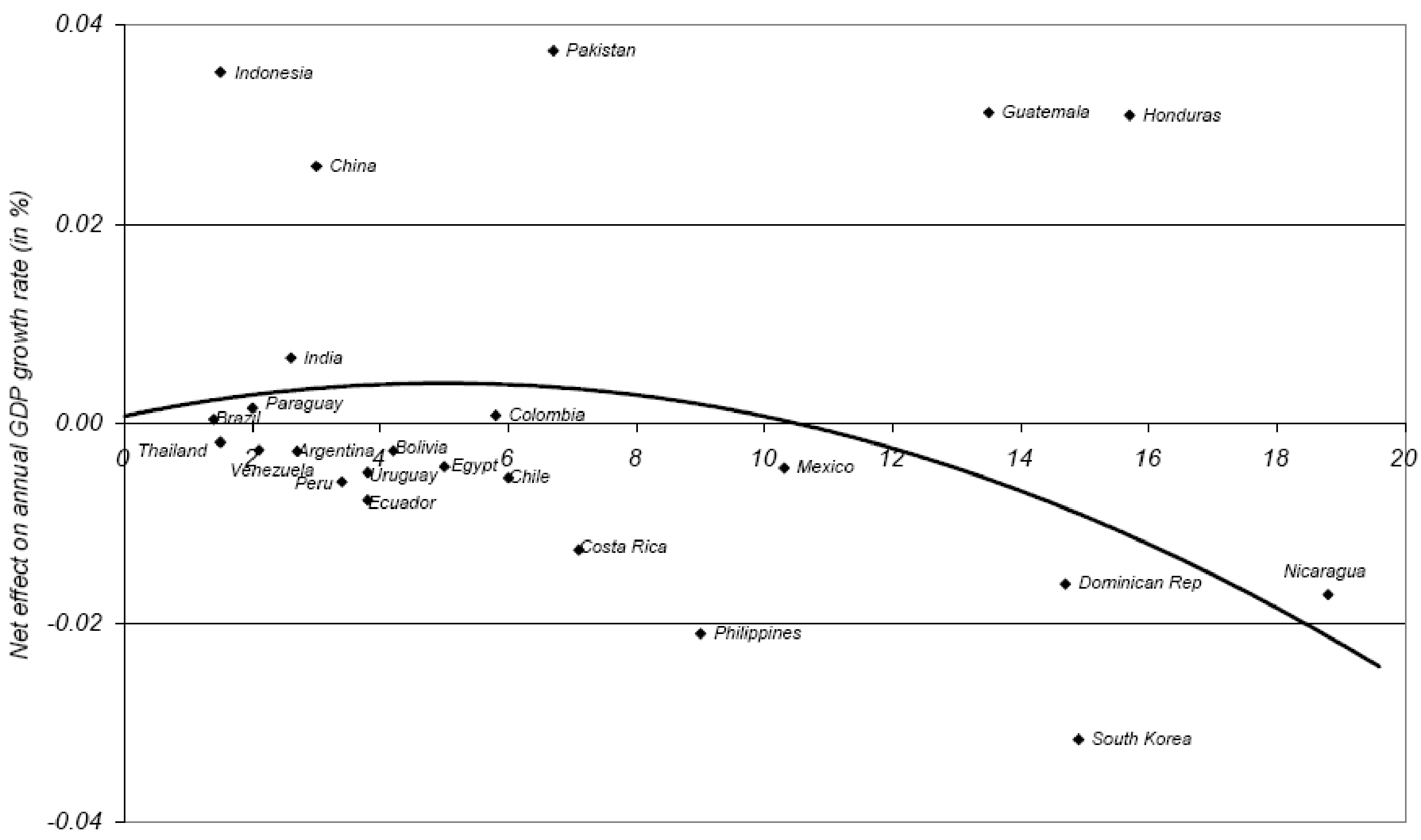

Emigration rate of tertiary educated workers (in \%)

Source: Beine et al. (2003) 